\title{
A VANGUARDA PARTICIPACIONISTA BRASILEIRA (1954-1973)
}

\section{The Brazilian participationist vanguard (1954-1973)}

\author{
Vinicius Spricigo* \\ Luciana Martha Silveira**
}

\begin{abstract}
RESUMO
As posições teóricas do artista plástico Hélio Oiticica, e a sua atuação cultural na segunda metade da década de 60 , aparecem, na maioria das vezes, como oposição àquelas defendidas pelo poeta e crítico de arte Ferreira Gullar, "revelando" um embate, discutido pela historiografia desse período, entre uma vanguarda artística modernizante e uma arte engajada de esquerda. Entretanto, no que diz respeito à formulação de uma vanguarda brasileira, e em muitos aspectos relativos ao envolvimento do artista em questões sociais e políticas, podemos encontrar muitos pontos em comum nas idéias defendidas pelos dois artistas. No texto que segue, indicaremos algumas convergências no modo como Hélio Oiticica e Ferreira Gullar teorizaram a vanguarda brasileira, a partir de transformações no sistema da arte especialmente no objeto artístico (obra aberta) e na recepção do espectador (participação) -, envolvendo também o tema do engajamento do artista em questões sociais e políticas do país. Defenderemos aqui a hipótese de que, tanto na poética de Oiticica, quanto no pensamento de Gullar, conceitos estéticos como obra aberta e participação do espectador estão vinculados com questões sociais e políticas, questionando assim as opiniões de que o artista carioca seria um modelo de "vanguardista" e o poeta maranhense um modelo de "artista engajado". Finalmente, este trabalho intenciona analisar criticamente a questão da validade e das especificidades de uma vanguarda artística fora dos grandes centros da arte mundial.
\end{abstract}

Palavras-chave: Hélio Oiticica, vanguarda brasileira, nova objetividade brasileira.

* Mestrando do Curso de Pós-graduação em Tecnologia do Centro Federal de Educação Tecnológica do Paraná. Bolsista da Coordenação de Aperfeiçoamento de Pessoal de Nível Superior (Capes).

** Professora do Curso de Pós-graduação em Tecnologia do Centro Federal de Educação Tecnológica do Paraná. Doutora em Comunicação e Semiótica pela PUC-SP. 


\begin{abstract}
The theoretical propositions of the Brazilian artist Hélio Oiticica seem to be the opposite of those proposed by the critic and poet Ferreira Gullar. It seems to reveal an opposition between an artistic avant-garde and an engaged art. However, both the Oiticica's formulation of a Brazilian avantgarde and the Gullar's ideas related to the social and political engagement of the artist reveal similar points. In the text that follows, we will indicate some convergences in the ways that Hélio Oiticica and Ferreira Gullar thought the Brazilian avant-garde, through the transformations in the art system - specially in the artwork (the open work) and in the spectators reception (participation) -, and their concerns about the political engagement of the artists. Our claim is that both Oiticica's poetics and Gullar's criticism have aesthetical concepts, such as the open work and the spectators participation, linked with political and social issues. We will also rise questions about the labels of "vanguardist" and "engaged artist" applied to Oiticica and Gullar respectively. Finally, this work aims at analyse criticaly the value and the characteristics of an artistic avant-garde out of the big centres of the international art.
\end{abstract}

Key-words: Hélio Oiticica, Brazilian Avant-garde, Brazilian New Objectivity.

Se quisermos definir uma posição específica para o que chamamos de vanguarda brasileira, teremos que procurar caracterizar a mesma como fenômeno típico brasileiro, sob pena de não ser vanguarda nenhuma, mas apenas uma falsa vanguarda, epígono da americana ou da francesa. ${ }^{1}$

"É possível em um país subdesenvolvido uma arte experimental de vanguarda?"2 A questão foi colocada pela curadora da décima Documenta, ${ }^{3}$ Catherine David, na abertura do texto $O$ Grande Labirinto, publicado no catálogo da primeira exposição retrospectiva da obra de Hélio Oiticica, realizada em Roterdã, Paris, Barcelona, Lisboa e Minneapolis, doze anos após

1 OITICICA, H. Aspiro ao grande labirinto. Rio de Janeiro: Rocco, 1986. p. 110.

2 DAVID, C. O grande labirinto. In: OITICICA, H. Hélio Oiticica. Rio de Janeiro: Centro de Artes Hélio Oiticica, 1992. p. 248

3 Realizada a cada cinco anos na cidade de Kassel, na Alemanha, a Documenta é uma das principais exposições internacionais de arte contemporânea, ao lado da Bienal de Veneza. A décima Documenta (1997) teve como curadora Catherine David, que adotou uma abordagem "retroperspectiva", revisando criticamente os 50 anos de Documenta e fazendo um prognóstico para o futuro da arte. 
a morte do artista no Rio de Janeiro, em 1980. Como reconhece Catherine David, a pergunta

\footnotetext{
...denuncia também uma relação antiga e resistente, com base na ignorância, na condescendência e no paternalismo, conivente com as culturas ditas periféricas e que levou à ocultação permanente, ao mascaramento (sob as formas do folclore ou do exotismo) ou mesmo à marginalização de pensamentos e obras de peso surgidos fora das "reconhecidas" capitais da modernidade. ${ }^{4}$
}

Como não poderia ser diferente, após essa retrospectiva internacional, a obra e o pensamento de Hélio Oiticica também foram redescobertos no Brasil. A necessidade de uma poética como a de Oiticica ser apresentada primeiro nos centros de legitimação da arte internacional para depois adquirir o devido reconhecimento no seu país de origem, também é um fato que atesta "uma relação antiga e resistente" entre as culturas centrais e as culturas "ditas" periféricas. Uma relação que muitas vezes foi diagnosticada como dependência cultural. A luta para superar essa dependência e formar uma arte genuinamente brasileira foi uma marca das vanguardas artísticas brasileiras durante todo o século 20. O modernismo brasileiro fundado pela Semana de 1922, nossa primeira vanguarda artística, foi também o ponto de partida de um projeto de cultura nacional, e da busca pela "brasilidade" da nossa arte. Enquanto na Europa, o modernismo contestava as especificidades locais e pregava um "mito" universalista, no Brasil o movimento modernista despertava a questão de uma arte brasileira. "Paradoxalmente, a arte moderna 'internacionalista' deflagra e encaminha a cultura brasileira à sua auto-indagação." ${ }^{5}$ Uma singularidade do modernismo latino americano.

Nos anos 60, período em que Hélio Oiticica formulou a sua teoria sobre um "estado geral da arte brasileira de vanguarda", a Nova Objetividade, e ainda hoje, o debate cultural brasileiro era marcado pela necessidade de afirmação da cultura brasileira diante dos modelos externos. Naquele momento, o projeto cultural iniciado no modernismo havia se dividido em duas correntes, gerando um impasse entre uma vanguarda modernizante e um projeto nacional-popular, entre uma arte "vanguardista" e uma arte "engajada". Ambos os projetos colocavam soluções distintas para a superação da nossa

4 DAVID, op. cit., p. 248

5 ZILIO, C. Da Antropofagia à Tropicália. In: NOVAES, A. O nacional e o popular na cultura brasileira - artes plásticas e literatura. São Paulo: Brasiliense, 1983. p. 14 
dependência cultural: o primeiro, por meio da modernização da sociedade e da atualização da nossa arte com o desenvolvimento da arte internacional; o segundo, pela proposição de uma arte vinculada às nossas raízes e ao nosso próprio subdesenvolvimento, propondo um modelo alternativo àqueles propostos pelos países desenvolvidos.

Se inicio um texto que tem como objetivo analisar o conceito de vanguarda brasileira nos anos 60 falando sobre a problemática da identidade cultural, é justamente porque o conceito de uma vanguarda participacionista, teorizado por Hélio Oiticica, foi marcado pelo debate sobre a identidade cultural brasileira. A hipótese que aqui será apresentada é a seguinte: o ponto de intersecção do projeto construtivo brasileiro, com a nossa tradição modernista (antropofagia), e com as propostas anti-imperialistas e de engajamento da esquerda nacional foi o terreno no qual Oiticica fundamentou a sua teoria sobre a vanguarda brasileira, a Nova Objetividade.

A periodização proposta neste trabalho inicia em 1954, com as experiências formais inauguradas pela démarche de Lygia Clark que culminaram no movimento neoconcreto e no rompimento com o suporte tradicional da pintura (o quadro de cavalete) e a participação do espectador. Já o ano de 1973, data da publicação do texto Brasil-Diarréia, marca o afastamento de Hélio Oiticica do cenário artístico e dos debates sobre a cultura brasileira. ${ }^{6}$ Essa delimitação cronológica marca, portanto, não somente o período de existência da vanguarda brasileira denominada Nova Objetividade, ${ }^{7}$ mas todo o período em que Hélio Oiticica esteve preocupado com a sua teorização.

Hoje, quando olhamos para a "história" das artes visuais no Brasil, os anos 60 aparecem marcados pela oposição entre o nacional-popular e o vanguardismo, e, muitas vezes, Ferreira Gullar e Hélio Oiticica tornam-se, nesse panorama, modelos do artista engajado e do artista experimental de vanguarda. Contudo, tanto os textos de Gullar que defendem a arte nacional tocam em questões relativas ao experimentalismo estético, quanto os trabalhos de Oiticica abarcam questões pertinentes ao engajamento do artista nos problemas sociais e políticos brasileiros. Ferreira Gullar, apesar de dedicar toda a sua obra à literatura, foi, ao lado de Mário Pedrosa, um dos maiores críticos

\footnotetext{
6 No período em que residiu em Nova lorque, entre 1970 e 1978, e mesmo após o seu retorno ao Rio de Janeiro, o artista aproximou-se de uma cultura underground e acabou situando-se à margem do circuito das artes visuais.

$7 \mathrm{Na}$ verdade, é difícil precisar o término da Nova Objetividade, justamente por ser um "estado geral da arte de vanguarda brasileira" e não um movimento coeso. No entanto, esse término pode ser identificado entre os anos de 1968 e 1969, que marcam, respectivamente, o ofuscamento do termo Nova Objetividade sob o fenômeno Tropicália e o exílio dos seus principais artistas.
} 
das artes plásticas brasileiras. Mesmo no momento de maior envolvimento seu com o projeto do Centro Popular de Cultura (CPC), e de "negação" da sua obra neoconcreta, Gullar redigiu textos importantes para a reflexão das artes visuais no Brasil, até mesmo contradizendo e repensando o projeto nacional-popular e o seu próprio engajamento. Por outro lado, Hélio Oiticica, que desenvolveu a sua poética a partir da implosão do projeto construtivo brasileiro efetuada pelo neoconcretismo, sempre questionou a elitização, o esteticismo e o intelectualismo nas artes plásticas. Além disso, Oiticica foi profundamente influenciado por Gullar, principalmente no que diz respeito ao papel social da arte e à necessidade de engajamento do artista. Nesse sentido, vale a pena, por meio de uma reaproximação desses dois artistas, obviamente sem desconsiderar suas diferenças, repensar a oposição entre arte engajada e vanguardismo, e pensar a vanguarda brasileira nos anos 60 , como um movimento ambivalente e contraditório, assim como a atuação e o pensamento de seus artistas. ${ }^{8}$

O movimento neoconcreto marcou o encontro teórico e poético entre Hélio Oiticica e Ferreira Gullar. O neoconcretismo foi responsável pelas principais transformações estruturais no campo das artes visuais no Brasil, como a superação dos suportes tradicionais (pintura e escultura), a proposição de novos meios para a criação artística (objetos, ambientes, apropriações etc.) e uma modificação radical na recepção das obras de arte (participação). A "tendência ao objeto" e a "participação do espectador" foram também duas das principais tendências de um "estado típico da arte brasileira de vanguarda", assinaladas por Oiticica no Esquema Geral da Nova Objetividade (no total, ele destacou seis). Nesse sentido, a passagem do quadro de cavalete para o objeto e a participação do espectador foram contribuições do neoconcretismo, que fundamentaram a conceituação que Oiticica fez de uma vanguarda brasileira. Às questões estruturais formuladas pelo neoconcretismo, somava-se ainda um problema de ordem social, o "engajamento" do artista. ${ }^{9}$ Oiticica acreditava que dois processos ocorreram paralelamente no desenvolvimento da arte brasileira de vanguarda: um "estrutural", de negação e superação do quadro de cavalete e tendência para o objeto, e outro "dialético realista", de participação social. $\mathrm{O}$ neoconcretismo seria o ponto de partida do esquema que Hélio Oiticica

8 Carlos Zilio justapõe as figuras de Ferreira Gullar e Hélio Oiticica. No entanto, Zilio enfatiza o modo singular como Oiticica enfocou as questões de uma arte nacional, deixando as singularidades do pensamento de Gullar em segundo plano. Isso se deve, em grande parte, ao momento no qual o texto foi redigido, marcado pela revisão do nacional-popular na cultura brasileira. ZILIO, op. cit.

9 No momento em que Hélio Oiticica redigiu o Esquema geral da Nova Objetividade, a participação social do artista se colocava de maneira dramática, devido ao fato de que os desejos por reformas sociais e políticas do final dos anos 50 foram imobilizados pelo governo militar instaurado em 1964 . 
utilizou para explicar esse desenvolvimento "estrutural/realista" da vanguarda brasileira nos anos 60; na medida em que, ao reformular o projeto construtivo brasileiro, ${ }^{10}$ o neoconcretismo reinseriu no desenvolvimento desse, formulações estruturais e sociais que estavam presentes nos movimentos históricos de vanguarda (construtivismo, neoplasticismo, dadaísmo e surrealismo), ${ }^{11}$ bem como problemas pertinentes à realidade social brasileira. Nesse ponto de encontro de preocupações estéticas e éticas, Oiticica assinalou o pioneirismo de Ferreira Gullar e do movimento neoconcreto.

Cabe notar aqui que esse processo "realista" (...), já se havia manifestado no campo poético, onde Gullar, que na época Neoconcreta estava absorvido em problemas de ordem estrutural e na procura de um "lugar para a palavra", até a formulação do nãoobjeto, quebra repentina com toda premissa de ordem transcendental para propor uma poesia participante e teorizar sobre um problema mais amplo que seja o da criação de uma cultura participante dos problemas brasileiros que afloravam. ${ }^{12}$

Hélio Oiticica não via ruptura na posição defendida por Gullar na época do seu envolvimento com as propostas do Centro Popular de Cultura e da publicação do livro Cultura posta em questão, com as posições defendidas pelo mesmo dentro do movimento neoconcreto. Segundo Oiticica, o que ocorreu foi "um verdadeiro processo de passagens para o objeto e para proposições dialético-pictóricas". ${ }^{13}$ Hélio Oiticica identificou também que a mesma passagem ocorreu paralelamente na sua própria poética.

10 Aqui, defendo claramente uma idéia antropofágica, de que aquilo que de fato aconteceu com o projeto construtivo brasileiro não foi um "transplante" do construtivismo no Brasil, mas a sua reelaboração diante das especificidades brasileiras.

11 Muito embora o manifesto neoconcreto renegasse as vertentes irracionais das vanguardas históricas (dada e surrealismo), a poética pós-neoconcreta de Hélio Oiticica realizou a síntese dessa corrente com o projeto construtivo, "organizando o delírio", nas palavras de Haroldo de Campos, ou delirando na organização.

12 OITICICA, 1992, op. cit., p. 111

13 Ibid., p. 112 
uma participação coletiva (vestir capas e dançar), participação dialético-social e poética (Parangolé poético e social de protesto com Gerchman), participação lúdica (jogos, ambientações, apropriações)... ${ }^{14}$

Como percebemos, o artista carioca distinguiu várias maneiras de participação do espectador, mas fica claro que uma dessas maneiras é aquilo que ele chama de "participação social". Nessa perspectiva, aquilo que Hélio Oiticica chamava de participação social era algo que já estava latente quando Lygia Clark e o movimento neoconcreto instauram a abertura da obra de arte e a participação do espectador. Enfim, aquelas três tendências destacadas com características de uma vanguarda artística brasileira - tendência para o objeto, participação do espectador, e tomada de posição em relação a problemas políticos, sociais e éticos - estavam inter-relacionadas dentro do Esquema Geral da Nova Objetividade. Nota-se ainda, na leitura do texto, a preocupação do artista com uma problemática que foi central para a discussão das artes visuais nos anos 60: as relações entre arte e vida, entre estética e política. Em suma, Oiticica e Gullar apreenderam justamente uma tensão que existia entre a necessidade do artista de aproximar-se da esfera social, mas a sua impossibilidade de abandonar o campo simbólico. Assim, os dois itens destacados anteriormente no manifesto da Nova Objetividade (quebra do quadro e chegada ao objeto, e participação do espectador) confluem para uma outra tendência da vanguarda brasileira nos anos 60 , "a necessidade da tomada de posição em relação a problemas políticos, sociais e éticos". ${ }^{15}$ No item do Esquema Geral da Nova Objetividade reservado à participação social, Hélio Oiticica destinou um longo trecho à poética e às idéias de Ferreira Gullar. Nas suas palavras:

Essas, idéias, ou linha de pensamento no sentido de uma "arte participante" (...) já há alguns anos vinham germinando de maneira clara e objetiva na obra de alguns poetas e teóricos, que pela natureza de seu trabalho possuíam maior tendência para a abordagem do problema. A polêmica suscitada aí tornou-se como que indispensável àqueles que em qualquer campo criativo estão procurando criar uma base sólida para uma cultura tipicamente brasileira, com características e personalidade próprias. Sem dúvida

14 OITICICA, 1992, p. 113.

15 Ibid., p. 115. 
a obra e as idéias de Ferreira Gullar, no campo poético e teórico, são as que mais criaram nesse período, nesse sentido. Tomam hoje uma importância decisiva e aparecem como um estímulo para os que vêem no protesto e na completa reformulação políticosocial uma necessidade fundamental na atualidade cultural. O que Gullar chama de participação é, no fundo essa necessidade de uma participação total do poeta, do artista, do intelectual em geral, nos acontecimentos e nos problemas do mundo, consequentemente influindo e modificando-os; um não virar as costas para o mundo para restringir-se a problemas estéticos, mas a necessidade de abordar esse mundo com uma vontade e um pensamento realmente transformadores, nos planos ético-político-social. O ponto crucial dessas idéias, segundo o próprio Gullar: não compete ao artista tratar de modificações no campo estético como se for a este uma segunda natureza, um objeto em si, mas sim de procurar, pela participação total, erguer os alicerces de uma totalidade cultural, operando transformações profundas na consciência do homem, que de espectador passivo dos acontecimentos passaria a agir sobre eles usando os meios que lhe coubessem: a revolta, o protesto, o trabalho construtivo para atingir essa transformação, etc. O artista, o intelectual em geral, estava fadado a uma posição cada vez mais gratuita e alienatória ao persistir na velha posição esteticista, para nós hoje oca, de considerar os produtos da arte como uma segunda natureza onde se processariam as transformações formais decorrentes de conceituações novas de ordem estética. Definitivamente é esta posição esteticista insustentável no nosso panorama cultural: ou se processa essa tomada de consciência ou se está fadado a permanecer numa espécie de colonialismo cultural ou na mera especulação de possibilidades que no fundo se resumem em pequenas variações de grandes idéias já mortas. ${ }^{16}$

A longa citação acima revela uma outra faceta da proposta que Hélio Oiticica apresentou para a caracterização de uma vanguarda brasileira, além da vinculação entre objeto/participação (estética) e engajamento (política), já evidenciadas pelo que foi dito até agora. ${ }^{17}$ Esse novo elemento propõe situar a participação social dentro do contexto de afirmação de uma cultura nacional em oposição aos modelos artísticos internacionais.

16 OITICICA, 1992, p. 116

17 Vale ressaltar que, no Esquema geral da Nova Objetividade, as questões estéticas não estão subjugadas pelas de ordem política, e nem mesmo subordinam estas. No entanto, resta ainda analisar com maior profundidade as reverberações que a participação política no campo simbólico propaga para a sociedade e principalmente quais são suas conquistas políticas efetivas. 
Tanto Ferreira Gullar quanto Hélio Oiticica trataram das questões estéticas e políticas da vanguarda nacional dentro de uma esfera mais ampla de discussão da cultura brasileira. Veremos a seguir como as idéias desses artistas, apesar de suas singularidades, parecem convergir em alguns pontos.

A problemática de uma cultura nacional e de uma arte engajada já estava presente no obra Cultura posta em questão, de Ferreira Gullar - citada por Oiticica no Esquema Geral da Nova Objetividade Brasileira -, mas foi formulada mais densamente numa série de artigos publicados na Revista Civilização Brasileira, em 1965, eque posteriormente foram reunidos no formato de livro com o título Vanguarda e subdesenvolvimento, publicado em 1969. Logo no início do livro, fica claro que Ferreira Gullar desloca a discussão sobre o "caráter alienante" do "vanguardismo" e o "caráter retrógrado" do realismo que marcavam um embate entre vanguarda e engajamento - para a contestação do mito universalista do conceito de vanguarda, e para o entendimento do que significava um conceito de vanguarda artística no contexto brasileiro. ${ }^{18}$ Na verdade, ele criticava o "desvio mecanicista" que o concretismo brasileiro havia tomado a partir do projeto inicial das vanguardas históricas construtivas, reiterando sua crítica formulada inicialmente no manifesto neoconcreto. Desse modo, as idéias do autor de Vanguarda e subdesenvolvimento aparecem como uma continuidade das críticas neoconcretas ao concretismo, por meio das proposições participativas. No entanto, não podemos desconsiderar que outros elementos somam-se à essa crítica como, por exemplo, uma revisão do radicalismo "cepeciano", que desconsiderava os problemas estéticos e culturais em nome de uma panfletagem política - sem deixar é claro de exaltar suas virtudes -, e o desvio da participação para uma estética da agressão. ${ }^{19}$

$\mathrm{Na}$ segunda parte do livro, o poeta maranhense definiu as vanguardas artísticas com base no conceito de "obra aberta", de Humberto Eco, que enfatiza a ambigüidade e a pluralidade de significados da obra de arte moderna. ${ }^{20}$ Contudo, Gullar deslocou a análise da "obra aberta" do campo da teoria da informação, no qual Eco o formulou inicialmente, para o terreno da filosofia, mais precisamente para o materialismo histórico: “...não se pode reduzir a questões puramente formais a problemática da comunicação e da 'abertura'. 1969. p. 19

18 GULLAR, F. Vanguarda e subdesenvolvimento. Rio de Janeiro: Civilização Brasileira,

$19 \mathrm{Na}$ análise desse problema, Gullar se refere claramente ao Teatro Oficina, contudo, podemos pensar que a mesma crítica caberia à radicalização de Oiticica em obras como Homenagem a Cara de Cavalo. $\mathrm{Na}$ formulação deste trabalho, Hélio Oiticica cita a influência da obra de Herbert Marcuse, considerada por Gullar como perniciosa. GULLAR, op. cit., p. 22-23.

20 GULLAR, op. cit., p. 51-52. 
(...) Tal constatação obriga-nos a considerar o problema da comunicação, não como um acontecimento meramente físico, sensorial, mas como um fato histórico, isto é, inserido no processo social e só possível nele". ${ }^{21}$

Segundo Gullar, o pensamento dialético e a arte moderna seriam reflexos do mesmo processo de transformação da sociedade burguesa. Assim, é a mesma realidade que provocava transformações no campo da arte, acarretando na abertura das obras, que levava o pensamento filosófico ao materialismo dialético. Nas suas palavras, "a 'obra aberta' se mostra como conseqüência inevitável da própria evolução social no plano da arte". ${ }^{22}$ É nesse sentido que o texto de Gullar pode ser entendido como uma revisão da sua Teoria do Não-objeto. Na época do neoconcretismo, a sua atenção estava voltada para as transformações estruturais pelas quais passava a arte brasileira naquele momento, já em 1965, ele buscava compreender as relação dessas transformações estruturais com a realidade social. ${ }^{23}$ Longe de rotular a obra de Hélio Oiticica como "vanguardista", ou identificar o artista como "alienado", Gullar afirma que os Parangolés, são uma tomada de consciência de que a abertura da obra não é puramente uma abertura de linguagem, mas uma abertura para o mundo. Assim, o artista carioca, sem abandonar o seu "idealismo" retornava à realidade. ${ }^{24}$

Após definir um conceito de vanguarda com base na Teoria da Obra Aberta, de Umberto Eco, Ferreira Gullar buscou na teoria marxista, a relação existente na arte, entre o particular e o universal, com o objetivo de criticar o universalismo da arte moderna. Uma vez que existe uma divisão entre países periféricos e centrais, e não podemos falar num capitalismo universal sem desconsiderarmos essas diferenças, o mesmo acontece com a arte. São as especificidades particulares da arte de cada país, centrais ou periféricos, que constroem a universalidade da arte. Cabe ao artista buscar conhecer e expressar a realidade social na qual está inserido. ${ }^{25} \mathrm{Assim}$, "a definição de arte de vanguarda num país subdesenvolvido deverá surgir do exame das características sociais e

\footnotetext{
21 GULLAR, op. cit., p. 56

22 Ibid., p. 58.

23 A necessidade de explicar ou relacionar transformações estruturais com modificações sociais já antecipava algumas preocupações da nova sociologia cultural, evidenciando que a questão da autonomia da arte moderna é relativa em países periféricos, onde os campos simbólicos não se estruturaram com a mesma autonomia assistida nos países centrais. CANCLINI, N. Culturas hibridas: estratégias para entrar e sair da modernidade. 2. ed. São Paulo: Edusp, 2003. p. 67-75.

24 No entanto, não podemos deixar de frisar que Gullar entende como participação social a adesão ao projeto do CPC e a adoção de um método materialista/nacionalista para a criação artística, diferentemente de Oiticica, que ele diz não ter abandonado ainda um certo "idealismo". GULLAR, op. cit., p. 65

25 GULLAR, op. cit., p. $78-81$.
} 
culturais próprias a esse país e jamais da aceitação ou da transferência mecânica de um conceito de vanguarda válido nos países desenvolvidos". ${ }^{26}$ Ferreira Gullar partia do pressuposto de que éramos um país periférico e dependente, e a única maneira de confrontar criticamente os modelos artísticos externos, que representam um universalismo imperialista, seria na nossa condição de subdesenvolvimento e dependência. ${ }^{27}$ Essa perspectiva tornava-se estreita na medida em que reduzia todo o debate sobre a vanguarda à luta contra os "estrangeirismos" e "modismos", e enfatizava a formação de uma arte nacional "pura". Nesse sentido, a visão marxista ortodoxa de Ferreira Gullar o impedia de avançar na discussão sobre o contato dos modelos externos com o nosso "chão cultural", para além das questões abertas pelo modernismo dos anos 20 , que já identificava o caráter híbrido (antropofágico) da nossa cultura. Além disso, nota-se nas palavras do autor de Vanguarda e subdesenvolvimento uma cisão entre arte erudita de vanguarda e arte popular, o que talvez explicaria com maior clareza por que, no campo poético, ele abandonou a poesia neoconcreta para produzir literatura de cordel.

Não estaríamos prontos - desenvolvidos o suficiente, na opinião de Gullar - para uma poesia de vanguarda como a neoconcreta. No estágio de desenvolvimento que apresentávamos nos anos 60, o cordel seria a melhor expressão da cultura brasileira. Gullar parecia desconsiderar o próprio fato de que, apesar do subdesenvolvimento econômico e da nossa dependência como países periféricos, a arte concreta havia germinado no Brasil, produzindo o neoconcretismo, um movimento de vanguarda de características singulares. Seria isso alguma aberração, ou o fato assinalava uma ambivalência, revelando aspectos "modernos" e "arcaicos" da nossa modernidade? Hélio Oiticica, ao incorporar os debates neoconcretos sobre as mudanças estruturais da arte (abertura da obra), a problemática da participação social, e a questão da cultura nacional dentro da sua poética e da sua teorização de uma vanguarda brasileira, pensou a complexidade e as contradições dos problemas de uma identidade nacional no contexto brasileiro em outra perspectiva, enfrentando criticamente o "absurdo" da existência de uma arte de vanguarda num país subdesenvolvido.

Apesar da participação de Hélio Oiticica no movimento neoconcreto, é no desenvolvimento posterior ao neoconcretismo que o artista desenvolveu

26 GULLAR, op. cit., p. 78-81.

27 Ferreira Gullar tem uma visão "etapista" da história, ele acredita que a nossa arte deve expressar o nosso subdesenvolvimento até o ponto em que o desenvolvimento econômico nos deixe aptos a produzir um tipo de arte de vanguarda nos moldes dos países desenvolvidos. 
as suas propostas mais radicais, como os Parangolés e os Penetráveis. Nesses trabalhos, as proposições de uma antiarte ambiental, uma tendência ao objeto e à participação do espectador, que fundamentaram a sua proposição de uma vanguarda brasileira, já estavam suficientemente maduras. Analisaremos aqui a obra Tropicália, pois no entorno desse trabalho estão as formulações de Oiticica acerca da Nova Objetividade, e as suas articulações sobre a problemática da cultura brasileira. A ligação entre a obra Tropicália e a Nova Objetividade é assinalada pelo próprio Hélio Oiticica num texto de março de 1968.

Da idéia e conceituação de 'Nova Objetividade', criada por mim em 1966, nasceu a Tropicália (...) Com a teoria da Nova Objetividade queria eu instituir e caracterizar um estado da arte brasileira de vanguarda, confrontando-o com os grandes movimentos da arte mundial e objetivando um estado brasileiro da arte ou das manifestações a ela relacionadas. A conceituação da Tropicália, apresentada por mim na mesma exposição, veio diretamente desta necessidade fundamental de caracterizar um estado brasileiro. (...) Tropicália é a primeiríssima tentativa consciente, objetiva, de impor uma imagem obviamente 'brasileira' ao contexto atual da vanguarda e das manifestações em geral da arte nacional. ${ }^{28}$

O problema de um "estado brasileiro" para a arte, presente na conceituação da obra Tropicália, já havia sido tratado pelo artista carioca no primeiro item do Esquema Geral da Nova Objetividade Brasileira, quando Oiticica falou de uma "vontade construtiva geral", que seria uma marca dos "movimentos inovadores brasileiros":

Até mesmo no Movimento de 22 poder-se-ia verificar isto, sendo a nosso ver, o motivo que levou Oswald de Andrade à celebre conclusão de que seria nossa cultura Antropofágica, ou seja, redução imediata de todas as influências externas a modelos nacionais. Isto não aconteceria não houvesse latente na nossa maneira de apreender tais influências, algo de especial, característico nosso, que seria essa vontade construtiva geral. (...) A Antropofagia seria a defesa que possuímos contra tal domínio exterior, e a principal arma criativa essa vontade construtiva... ${ }^{29}$

28 OITICICA, 1992, op. cit., p. 124

29 Ibid., p. 116. 
Desconsiderando as críticas que poderiam ser feitas à tentativa de Oiticica de inserir toda a arte brasileira dentro do desenvolvimento de um projeto construtivo - eliminando as especificidades de outras poéticas ou excluindo outras tendências não-construtivas -, vale a pena ressaltar novamente a preocupação do artista carioca com a caracterização de uma vanguarda brasileira dentro de um contexto internacional, ou seja, dialogando com as vanguardas internacionais mais importantes naquele momento, a Pop Art e o Nouveau-Realisme. Além disso, o mesmo aspecto combativo de afirmação da nossa cultura contra um "domínio exterior", presenciado no pensamento de Ferreira Gullar, reaparecem em Hélio Oiticica. A diferença está na "arma" escolhida pelos dois artistas para combater tal domínio. Enquanto para Gullar seria a afirmação do nosso subdesenvolvimento e da nossa cultura popular, para Oiticica seria uma "vontade construtiva" que se confunde com a própria idéia de antropofagia.

Freqüentemente ouvimos críticas à Tropicália, de Hélio Oiticica, alegando que essa obra não passaria de uma tentativa de criar uma imagem "pop" brasileira. Contudo, Oiticica afirmava claramente que buscava uma "nova linguagem com elementos brasileiros", justamente para confrontar os modelos artísticos externos e o mito universalista da arte brasileira. Acredito que Hélio Oiticica, no período da Nova Objetividade, influenciado pela situação brasileira e pelas idéias de Ferreira Gullar, tentava, com a sua teorização de uma vanguarda brasileira, encontrar um modelo de cultura nacional que fizesse frente aos modelos internacionais, propondo, ao menos no plano das idéias, a nossa independência, algo muito improvável no plano econômico. Entretanto, apesar de situar sua discussão no plano das idéias anti-imperialistas como Ferreira Gullar - mesmo para o radicalismo de Oiticica fugir do assunto seria "alienar-se" -, Hélio Oiticica compreendia a vocação antropofágica da nossa cultura, e, sem cair no "purismo" de Gullar, buscava pensar a nossa vanguarda dentro do desenvolvimento da arte internacional. Sentido de construtividade para Oiticica não seria uma especificidade somente da nossa arte, mas também uma característica geral da arte contemporânea. Assim, a vanguarda brasileira dialogava com o desenvolvimento da arte moderna internacional, principalmente com o expressionismo abstrato, a pop art e o novo-realismo.

Em 1973, no texto Brasil Diarréia, Hélio Oiticica retoma o problema da criação de uma linguagem brasileira para as artes visuais, aprofundando a crítica ao mito universalista da arte moderna, agora censurando um certo purismo identificado na defesa de uma cultura brasileira - segundo ele um conceito morto. 
A pressa em criar (dar uma posição) num contexto universal a esta linguagem-Brasil, é a vontade de situar um problema que se alienaria, fosse ele "local" (problemas locais não significam nada se fragmentam quando expostos a uma problemática universal; são irrelevantes se situados somente em relação a interesses locais; o que não quer dizer que os exclua, pelo contrário) - a urgência dessa "colocação de valores" num contexto universal, é o que deve preocupar realmente àqueles que procuram uma "saída" para o problema brasileiro. É um modo de formular e reformular os próprios problemas locais, desaliená-los e levá-los a conseqüências eficazes. Por acaso fugir ao consumo é ter uma posição objetiva? Claro que não. É alienar-se, ou melhor, procurar uma solução ideal, extra - o mais certo é sem dúvida, consumir o consumo como parte dessa linguagem. Derrubar as defesas que nos impedem de ver "como é o Brasil no mundo, ou como ele é realmente" - dizem: "estamos sendo invadidos" por uma "cultura estrangeira" como se isso fosse um pecado ou uma culpa - o fenômeno é borrado por um julgamento ridículo, moralista-culposo: "não devemos abrir as pernas à cópula mundial - somos puros" - esse pensamento, de todo inócuo, é o mais paternalista e reacionário atualmente aqui. Uma desculpa para parar, para defender-se - olha-se demais para trás - tem-se "saudosismos" às pampas - todos agem um pouco como viúvas portuguesas: sempre de luto, carpindo. CHEGA DE LUTO NO BRASIL!" 30

Hélio Oiticica não acreditava no puritanismo do particular como defesa aos modelos externos, principalmente norte-americanos, mas no confronto crítico da cultura brasileira com as demais culturas, e na tomada de consciência quanto aos problemas culturais brasileiros (a falta de caráter [diarréia], o cinismo, a hipocrisia e a ignorância, o que ele chama de convi-conivência). Para Oiticica, a saída para o "consumo" seria a vivência da realidade brasileira como ela realmente é.

A Tropicália, de Oiticica, surgiu da vivência do artista em sua realidade local:

...tudo começou com a formação do Parangolé em 1964, com toda a minha experiência com o samba, com a descoberta dos morros, da arquitetura orgânica das favelas cariocas e principalmente das

30 OITICICA, 1992, op. cit., p. 17-18. 
construções espontâneas, anônimas, nos grandes centros urbanos - $\mathrm{a}$ arte das ruas, das coisas inacabadas, dos terrenos baldios etc. ${ }^{31}$

Contudo, a essa assimilação da cultura popular, Oiticica somou um discurso artístico que advém de uma leitura que a arte construtiva faz de toda a história da arte ocidental, desde o Renascimento. Temos, desse modo, a mistura de uma cultura erudita, de origem européia, com uma cultura popular de origem afro-brasileira. ${ }^{32}$ De outra forma, o que distinguiria a vivência de Oiticica nos morros cariocas da dos demais moradores das favelas brasileiras se não é o fato de ele construir Parangolés, inseri-los numa narrativa sobre a história da arte e levá-los ao museu para "institucionalizá-los"? Mesmo acreditando que a afirmação de uma cultura nacional poderia nos ajudar a romper com a nossa situação de dependência, Hélio Oiticica não adotou uma visão puritana. Sua poética é híbrida por natureza, misturando elementos eruditos, populares e da cultura de massa. ${ }^{33}$

Após uma breve análise do modo como Ferreira Gullar e Hélio Oiticica pensaram a vanguarda e a cultura brasileiras nos anos 60 , retornamos ao questionamento que abriu este texto. É possível uma arte de vanguarda num país periférico? Ou nossas vanguardas artísticas trataram-se de constantes adaptações de modelos externos? Afinal, qual é a relação entre a Nova Objetividade Brasileira e as outras vanguardas internacionais do mesmo período, imitação ou diálogo? Poderíamos caracterizar a relação entre a arte dos países periféricos com a arte dos países centrais como dependência cultural? E entendendo-a como verdadeira, qual a ligação dessa dependência cultural com o "subdesenvolvimento" brasileiro?

No âmbito da crítica literária brasileira, Roberto Schwarz apresenta uma das mais lúcidas hipóteses de interpretação da relação entre a nossa dependência econômica como país periférico, advinda do colonialismo, e a importação de modelos dos países centrais no campo simbólico. Vejamos até que ponto a sua tese desenvolvida no texto "As idéias fora do lugar" introdução do livro sobre Machado de Assis, Ao vencedor as batatas - pode nos auxiliar na tarefa de responder às questões colocadas acima. Schwarz afirma que a nossa singularidade seria o descentramento das nossas idéias em

31 OITICICA, 1992, op. cit., p. 124.

32 Hélio Oiticica realizou, no espaço real, a aproximação que Pablo Picasso efetuou no plano pictórico, entre a cultura européia e o primitivismo africano.

33 Vale lembrar que, no final do principal Penetrável de Tropicália, encontrava-se um aparelho de 
relação ao seu uso na Europa. Um conceito como o modernismo, por exemplo, teria um sentido e um uso peculiar no Brasil, diferentemente do seu significado e aplicação na Europa. Nas suas palavras, "ao longo de sua reprodução social, incansavelmente o Brasil põe e repõe idéias européias, sempre em sentido impróprio" ${ }^{34}$ Essa hipótese foi formulada com base na análise da importação das idéias liberais para o Brasil no século 19. Aqui, o liberalismo não seria uma ideologia, como na Europa, mas um "ornamento" e justificativa para uma relação de "clientelismo" entre latifundiários e homens livres. Naquele período, o descentramento das idéias liberais seria a nossa singularidade. $\mathrm{Na}$ esfera econômica, o autor observava na dependência brasileira da escravidão e do capitalismo internacional, as razões históricas para esse deslocamento das idéias liberais.

Muito embora, Roberto Schwarz adote uma perspectiva dialética de interpretação do problema, separando a infraestrutura (produção) da superestrutura (cultura), ele não subordina as operações no campo simbólico àquelas ocorridas na esfera da produção. Antes, o autor busca encontrar as contradições que existem no campo simbólico, entre o "favor" e as idéias liberais. Contudo, mesmo portador de um marxismo mais "refinado", comparado com aquele adotado por Gullar, e produzindo uma análise muito mais densa do problema da "originalidade" da cultura brasileira, um ponto é comum para ambos os autores. No Brasil, o subdesenvolvimento econômico gera dependência cultural de modelos externos. As propostas que Gullar e Schwarz formulam com base nessa constatação é que são diferentes. Enquanto o primeiro acredita que uma arte genuinamente nacional seria nossa arma contra o imperialismo yankee, o segundo percebe, no processo de descentramento das idéias estrangeiras, a nossa singularidade.

No campo simbólico, acreditamos que Hélio Oiticica revelou um processo de "descentramento de idéias" artísticas. O modelo externo, nesse caso, seria o projeto construtivo, importado para o Brasil nos anos 50, via Escola de Ulm. Junto com a abstração geométrica construtiva, o Brasil também importou um sistema artístico autônomo, fundando instituições artísticas como os Museus de Arte Moderna do Rio e de São Paulo, e a Bienal. Entretanto, após o neoconcretismo, Hélio Oiticica demonstrou lucidamente, por meio de sua poética, que esses modelos não funcionavam "propriamente" no contexto brasileiro. Afinal, se o Brasil tivesse o mesmo desenvolvimento técnico e

34 SCHWARZ, Roberto. As idéias fora do lugar. In: SCHWARZ, Roberto. Cultura e politica. São Paulo: Paz e Terra, 2001.p. 77. 
econômico que a Suíça, provavelmente, em vez de produzir um Hélio Oiticica, produziria cópias fiéis de um Max Bill. Em primeiro lugar, o projeto construtivo não "conduziu esteticamente" o país ao desenvolvimento econômico, caindo num "desvio mecanicista", razão pela qual Oiticica negava a utopia construtiva de inserção no processo produtivo e passou a atuar no campo simbólico e político. Segundo, ao incorporar a participação do espectador e elementos de uma arte dita popular, a obra de Oiticica, por não se prestar mais à contemplação e ao consumo, não se enquadrava nos padrões das instituições artísticas. Nessa perspectiva, poderíamos tomar a Nova Objetividade, teorizada por Oiticica como o descentramento, a adaptação sofrida pelo projeto construtivo ao chegar ao solo brasileiro, e a Tropicália como a sua objetivação. ${ }^{35}$

O que pode validar a vanguarda artística que Oiticica denominou como Nova Objetividade diante das vanguardas internacionais do mesmo período é a compreensão de que ela dialogava, tanto com uma tradição artística brasileira de vanguarda (Semana de 22, concretismo e neoconcretismo), quanto com a pop art norte-americana e o novo-realismo francês. Dialogava ainda com a cultura popular brasileira e com a cultura "massiva". A Nova Objetividade possuía ainda uma característica singular, o descentramento e a reelaboração do projeto construtivo diante do choque com as nossas especificidades estruturais (sistema de produção, distribuição e recepção de obras de arte), culturais e sociais. São estas características que garantem a sua validade como experiência de vanguarda num país periférico.

Finalmente, deve-se assinalar que, apesar dos textos de Hélio Oiticica e Ferreira Gullar trazerem a marca do período no qual foram escritos, eles ainda se prestam à discussão atual sobre arte e cultura brasileiras. Reconhecer a nossa situação como países periféricos e as ambivalências e contradições do nosso modernismo - sem incorrer no erro de acreditar que existe um

35 Devemos ressaltar, no entanto, que Roberto Schwarz possui um conceito de vanguarda que contradiz as idéias discutidas neste artigo. Schwarz tem uma visão crítica das vanguardas construtivas e do tropicalismo. Os tropicalistas viam com bons olhos tanto a nossa tradição antropofágica, quanto a coexistência do arcaico com o moderno. Tomemos, como exemplo, a própria Tropicália de Oiticica, em que popular e moderno se misturam, e as tendências da arte internacional dão subsídios estéticos para a objetivação de uma realidade brasileira. Justamente esses aspectos são alvos da crítica de Schwarz, para quem o Tropicalismo produz alegorias do absurdo brasileiro. Embora Schwarz dirija sua crítica principalmente à musica, ao teatro e ao cinema tropicalista, a carapuça parece servir também para a ambientação de Oiticica. Crítico dialético, Roberto Schwarz defende o impulso revolucionário do cinema novo e da literatura contra o experimentalismo de vanguarda. Na sua opinião, o simbólico (literatura) possui uma combinação de forma e conteúdo revolucionário que não podemos encontrar nas alegorias tropicalistas. SCHWARZ, op.cit., p. 27-28. Ver ainda SCHWARZ, Roberto. O cinema e os fuzis. In: SCHWARZ, Roberto. O pai de familia e outros estudos. São Paulo: Paz e Terra, 1978; e SCHWARZ, Roberto. Nota sobre vanguarda e conformismo. In: SCHWARZ, Roberto. O pai de família e outros estudos. São Paulo: Paz e Terra, 1978. 
"modernismo ideal" nos países centrais -, é fundamental para a compreensão da situação atual da arte brasileira (marcada pelo esvaziamento dos projetos culturais) e do legado da vanguarda artística participacionista dos anos 60 . Para avaliar a herança neoconcreta, participacionista e vanguardista da poética de Hélio Oiticica e dar-lhe o devido reconhecimento no cenário brasileiro e internacional, devemos evitar as "visões conciliadoras" que negam a nossa situação como países periféricos (defendidas pelos ufanistas e pelos críticos de arte estrangeiros deslumbrados com os nossos artistas), mas também compreender que a relação da cultura brasileira com as demais não se reduz à dependência, entendida como importação e transplante de modelos externos.

\section{Referências}

CANCLINI, N. Culturas híbridas: estratégias para entrar e sair da modernidade. 2. ed. São Paulo: Edusp, 2003.

GULLAR, F. Vanguarda e subdesenvolvimento. Rio de Janeiro: Civilização Brasileira, 1969.

OITICICA, H. Hélio Oiticica. Rio de Janeiro: Centro de Artes Hélio Oiticica, 1992.

. Aspiro ao grande labirinto. Rio de Janeiro: Rocco, 1986.

SCHWARZ, R. Cultura e politica. São Paulo: Paz e Terra, 2001.

ZILIO, C. Da Antropofagia à Tropicália. In: NOVAES, A. O nacional e o popular na cultura brasileira - artes plásticas e literatura. São Paulo: Brasiliense, 1983. 